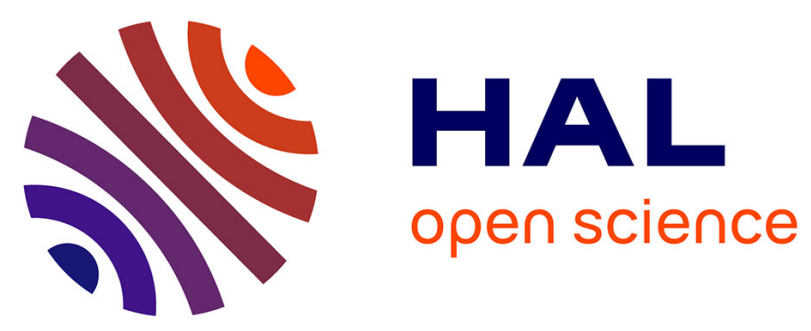

\title{
STUDY OF SUPPLY CHAIN VULNERABILITIES BASED ON COGNITIVE ENGINEERING AND ARIMA FORMAL MODELS
}

Jean-Marc Mercantini, Leïla Sakli, Jean-Claude Hennet

\section{- To cite this version:}

Jean-Marc Mercantini, Leïla Sakli, Jean-Claude Hennet. STUDY OF SUPPLY CHAIN VULNERABILITIES BASED ON COGNITIVE ENGINEERING AND ARIMA FORMAL MODELS. 11th International Conference on Integrated Modeling and Analysis in Applied Control and Automation (IMAACA), Sep 2018, Budapest, Hungary. hal-02372251

\section{HAL Id: hal-02372251 \\ https://hal-amu.archives-ouvertes.fr/hal-02372251}

Submitted on 20 Nov 2019

HAL is a multi-disciplinary open access archive for the deposit and dissemination of scientific research documents, whether they are published or not. The documents may come from teaching and research institutions in France or abroad, or from public or private research centers.
L'archive ouverte pluridisciplinaire HAL, est destinée au dépôt et à la diffusion de documents scientifiques de niveau recherche, publiés ou non, émanant des établissements d'enseignement et de recherche français ou étrangers, des laboratoires publics ou privés. 


\title{
THE $11^{\text {TH }}$ INTERnATIONAL CONFERENCE ON INTEGRATED MODELING AND ANALYSIS IN APPLIED CONTROL AND AUTOMATION
}

\author{
SEPTEMBER 17 - 192018 \\ BUDAPEST, HUNGARY
}

\section{IMAACA}

\author{
EDITED BY \\ AgOST INO BRUZZONE \\ GeneVIĖVe DAUPHIN-T ANGUY \\ SERGIO J UNCO
}

Printed in Rende (CS), Italy, September 2018

ISBN 978-88-85741-11-9 (Paperback)

ISBN 978-88-85741-10-2 (PDF) 


\title{
STUDY OF SUPPLY CHAIN VULNERABILITIES BASED ON COGNITIVE ENGINEERING AND ARIMA FORMAL MODELS
}

\author{
L. Sakli, J-M Mercantini, J-C Hennet
}

\author{
Aix-Marseille Université \\ Laboratoire des Sciences de l'Information et des Systèmes (UMR CNRS n 7296) \\ Domaine universitaire de Saint Jérôme \\ Avenue Escadrille Normandie-Niemen \\ 13397 Marseille cedex 20 \\ jean-marc.mercantini@lis-lab.fr
}

\begin{abstract}
This research concerns the formulation of models and methods for supply chains risk analysis. An ontological approach using the KOD method (Knowledge Oriented Design) has been implemented to clearly identify relationships between the concepts of supply chain, risk, vulnerability and disturbances (critical scenarios). As a result, conceptual models of supply chains facing risk situations and critical scenarios are proposed. From the resulting conceptual models and mathematical models proposed in the literature, a multi-stage supply chain model using ARIMA models incorporating the randomness of the demand has been elaborated. In order to adapt this model to scenario criticality, constraints on orders and inventories have been taken into account. Under critical disturbances on information flows (demand) and physical flows (quality of the product supplied), constraints can be reached and supply chain behaviours can evolve toward critical dynamics or even become unstable. Supply chain vulnerabilities has been assessed and discussed.
\end{abstract}

Keywords: Supply chain, Risk, Vulnerability, Cognitive Engineering, ARIMA, Simulation.

\section{INTRODUCTION}

New technologies and globalization increase the complexity of supply chains and therefore expose them to risks of different types. Faced with uncertainty, supply chains appear more sensitive in the context of competitive pressure, unpredictable and volatile global market demand. In particular, supply chains are sensitive to local disturbances and uncertainties related to demand, supplies or information. Several studies have been conducted to analyze the topic of risk especially in the context of the supply chain. In general, risk is a combination of a probability of occurrence of an adverse event and a measure of the severity of the consequences of this event in terms of damage or injury (ISO / CEI73). The concept of risk is significant only in the presence of targets vulnerable to the effects of hazards induced by accidents.

Due to the complex structures of today supply chains, a risk in a company may have consequences for other companies upstream or downstream. It thus threatens the entire chain. The resilient supply chain has the ability to adapt whatever the events to which the chain is subjected. Resilience is "the system's ability to return to a new stable situation after an accidental event". Taking into account that resilience is a multidimensional concept, Serhiy $\mathrm{Y}$ et al. define resilience of a supply chain as "the adaptive capability to prepare for unexpected events, respond to disruptions, and recover from them by maintaining continuity of operations at the desired level of connectedness and control over structure and function". To preserve the resilience of supply chains, the areas of risk analysis and risk management are currently acquiring great interest, both from the theoretical and applicative standpoints. It is necessary to have indicators of vulnerabilities in the chain to determine the sensitivity of the chain to adverse events and to characterize the system's lack of resilience.

This paper seeks to evaluate the vulnerability of supply chains. In agreements with the findings of (Gilbert 2005), we propose to use a time series representation of the supply chain in the form of an ARIMA (Auto Regressive Integrated Moving Average) model that propagates along the supply chain and makes possible to represent the bullwhip effect. The limits of validity of this model correspond to hitting positivity and capacity constraints as the result of strong disturbances on product flows. It is then possible to simulate the constrained system evolution and compute some vulnerability indicators related to the frequency of constraints saturation.

Due to a large amount of works in the areas of supply chain, risk, vulnerability and resilience, we were confronted with a large number of definitions that sometimes could be contradictory. In the first part of this paper, a conceptual analysis of supply chain and risk areas was carried out to clarify what might appear 
to be ambiguities. In section 2 , the problem of the disparity of terms and concepts is presented. In section 3 , the methodological approach, based on knowledge engineering, to address this problem is developed. In paragraphs 4 and 5, the ontological study is conducted to finally propose conceptual models linking the main concepts of the domains of supply chains and risks. In the second part of this paper, aspects of formal modeling and simulation are discussed.

\section{PROBLEM ANALYSIS}

The increased complexity of supply chains in recent years has naturally led to an increase in the number of potential points of weakness. By becoming more complex, they have become more vulnerable to the different disruptions they face (Chopra and Sodhi 2004). In addition, (Haywood 2002) indicates that the lack of a common understanding of the term "supply chain" represents a significant barrier to identifying vulnerabilities and implementing appropriate risk management methods.

The study of risk in supply chains was approached according to several fields of research. As suggested by (Zsidisin 2003), the term "risk" can be a source of confusion because it is perceived as a multidimensional concept. According to (Jüttner et al. 2003), this term can be used to designate internal or external uncertainties that reduce the predictability of the expected results. In this sense, "risk" refers to a source of risk and uncertainty, such as "political risks", "market risks" and "volatility of customer demand". According to the same author, the term can also be used to describe the consequences of these events. According to (Chopra 2004), there is no consensus on the definition of supply chain risks, nor on the definition of supply chain risk management.

If we focus on supply chain vulnerability, the literature shows that only a few studies have been done to date. Supply chain vulnerability is defined by (Juttner et al. 2003) as the propensity of risk sources and risk drivers to outweigh risk mitigating strategies, thus causing adverse supply chain consequences.

According to (Asbjørnslett 2009), the vulnerability of a supply chain is an intrinsic property. It represents the sensitivity of the chain to the effects of certain phenomena or disturbances. The concepts of consequence or damage have meaning only in relation to that of vulnerability. In other words, without vulnerability, there is no harm and therefore the risk is zero (Hennet et al. 2008, Hennet and Mercantini 2010).

As a conclusion, the literature review concerning studies of supply chain vulnerabilities has shown a domain with a large number of ambiguities du to the large number of definitions:

ambiguities within supply chain definitions, ambiguities within risk definitions, ambiguities within definitions of supply chain risk management,
- $\quad$ and ambiguities within definitions of supply chain vulnerability,

The notion of ontology and works currently developed by the scientific community of knowledge engineering can bring interesting answers to clarify these ambiguities. According to (Gruber 1993) and completed by (Borst 1997) et (Studer 1998), an ontology is a formal, explicit specification of a shared conceptualization. A conceptualization is an abstract, simplified view of the world that we wish to represent for some purpose, by means of concepts and their relationships. Ontologies structure a knowledge domain in highlighting concepts and semantic relations that are linking these concepts.

As part of this study, we do not aim to build the ontology of the domain of supply chains. Our aim is to highlight the differences in the definitions proposed by the actors in the domain and whether these differences are based on genuine conceptual differences, or are they just the different complementary aspects of the same reality. Thus, our ontological analysis is in the spirit of the definition of (Gruber 1993), with the intention of arriving at a common conceptualization. At the end of this analysis, we will propose a conceptual model of supply chains through which we will position the rest of our work and in particular, we will justify the choice of the variables selected for the simulation models.

\section{METHODOLOGICAL APPROACH}

\subsection{The methodological process}

The followed methodological process (Figure 1) consists in adopting approaches and methods from Knowledge Engineering (KE) combined with formal modelling and simulation.

KE methods are used in order to elaborate an ontological analysis of the domain as a basis for the development of conceptual models of supply chains, risks and vulnerabilities. The process is based on the "Knowledge Oriented Design" (KOD) method (Vogel 1988; Mercantini 2007). KOD was designed to guide the knowledge engineer in its task of developing knowledge based systems. This method was designed to introduce an explicit model between the formulation of a problem in natural language and its representation in the chosen formal language. The inductive process of $\mathrm{KOD}$ is based on the analysis of a corpus of documents, speeches and comments from domain experts, in such a way to express an explicit cognitive model (also called conceptual model).

From the resulting conceptual models, a multi-stage supply chain model using ARIMA (Auto Regressive Integrated Moving Average) models incorporating the randomness of the demand has been elaborated. Finally, supply chain vulnerability has been studied thank to the simulation of critical scenarios.

\subsection{The KOD method}

KOD is based on an inductive approach to explicitly express a cognitive model (or conceptual model) based 
on a corpus of documents, comments and experts' statements. The main features of this method are based on linguistics and anthropological principles. Its linguistics basis makes it well suited for the acquisition of knowledge expressed in natural language. Thus, it proposes a methodological framework to guide the collection of terms and to organize them based on a terminological analysis (linguistic capacity). Through its anthropological basis, KOD provides a methodological framework, facilitating the semantic analysis of the terminology used to produce a cognitive model (conceptualisation capacity). It guides the work of the knowledge engineer from the extraction of knowledge to the development of the conceptual model. The implementation of the KOD method is based on the development of three successive models: the practical models, the cognitive model and the software model (Table 1). Each of these models is developed according to the three paradigms: <Representation, Action, Interpretation / Intention>.

The Representation paradigm gives the KOD method the ability to model the universe such as experts represent it. This universe is made of concrete or abstract objects in relation. The KOD method provides methodological tools to develop the structure of this universe of knowledge according to this paradigm. The Action paradigm gives the KOD method the ability to model the behaviour of active objects that activate procedures upon receipt of messages. The Interpretation / Intention paradigm gives the KOD method the capability to model reasoning used by experts to interpret situations and elaborate action plans related to their intentions (reasoning capacity).

The practical model is the representation of a speech or document expressed in the terms of the domain, by means of "taxemes" (static representation of objects French word), "actemes" (dynamic representation of objects - French word) and inferences (base of the cognitive reasoning pattern). A "taxeme" is a minimum grammatical feature; it is the verbalisation of an object or a class of objects. An "acteme" is the verbalisation of an act or a transformation, a unit of behaviour. An inference is the act or process of deriving logical conclusions from premises known or assumed to be true. The cognitive model is constructed by abstracting the practical models. The cognitive model is composed of taxonomies, actinomies and reasoning patterns. The software model results from the formalization of a cognitive model expressed in a formal language independently of any programming language.

\subsection{The ontology building process using KOD}

Research work in Ontology Engineering has put in evidence five main steps for building ontologies (Dahlgren 1995; Uschold 1996; Aussenac-Gilles 2000; Gandon 2002):

1. Ontology Specification. The purpose of this step is to provide a description of the problem as well as the method to solve it. This step allows one to describe the objectives, scope and granularity size of the ontology to be developped.

2. Corpus Definition. The purpose is to select among the available information sources, those that will allow the objectives of the study to be attained.

3. Linguistic Study of the Corpus. It consists in a terminological analysis of the corpus in order to extract the candidate terms and their relations. Linguistics is specially concerned to the extent that available data for ontology building are often expressed as linguistic expressions. The characterization of the sense of these linguistic expressions leads to determine contextual meanings.

4. Conceptualization. Within this step, the candidate terms and their relations resulting from the linguistic study are analyzed. The candidate terms are transformed into concepts and their lexical relations are transformed in semantic relations. The result of this step is a conceptual model.

5. Formalization. The step consists in expressing the conceptual model by means of a formal language.

The projection of the KOD method on the general approach for developing ontology shows that KOD guides the corpus constitution and provides the tools to meet the operational steps 3 (linguistic study) and 4 (conceptualization) (Table 2). The KOD method has been already implemented for diverse research projects (Mercantini 2003; Mercantini 2004; Mercantini 2007; Mercantini 20015) in the domains of road safety, safety of urban industrial sites and conduct errors of industrial plants. 


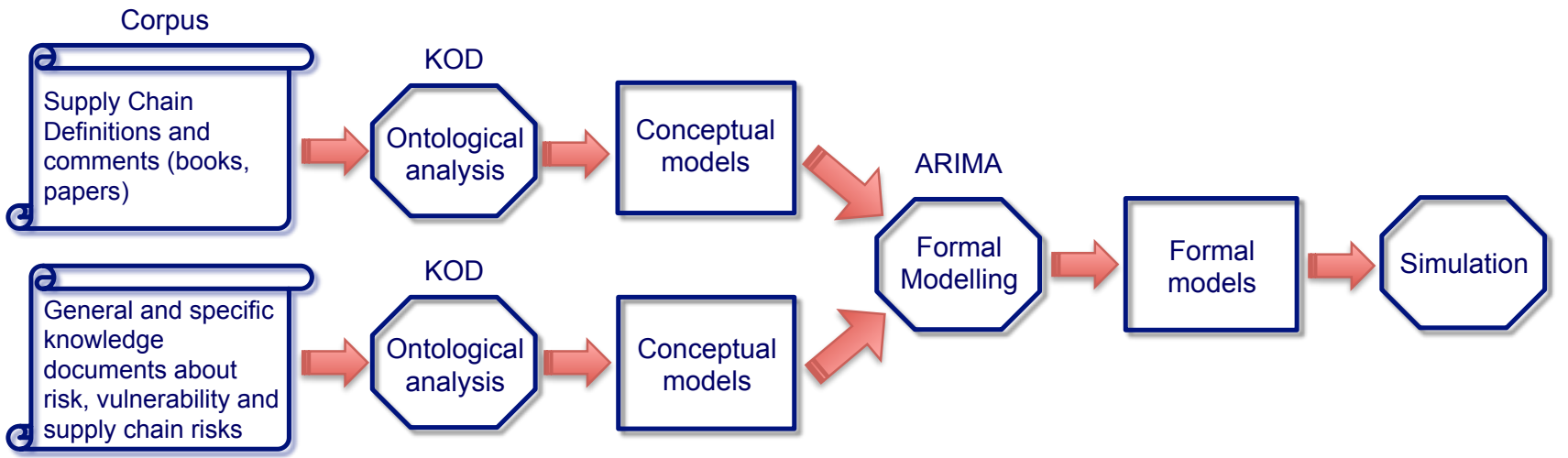

Figure 1: The implemented methodological approach for the Supply Chain Vulnerabilities Study

Table 1. KOD, the three modelling levels.

\begin{tabular}{|l|c|c|c|}
\hline $\begin{array}{c}\text { Paradigms } \\
\text { Models }\end{array}$ & Representation & Action & Interpretation \\
\hline Practical & $\begin{array}{c}\text { Taxeme: object static } \\
\text { representation }\end{array}$ & $\begin{array}{c}\text { Acteme: dynamic } \\
\text { representation of active } \\
\text { objects }\end{array}$ & Inferences \\
\hline Cognitive & $\begin{array}{c}\text { Taxonomy: object static } \\
\text { organization according to } \\
\text { theirs properties }\end{array}$ & $\begin{array}{c}\text { Actinomy: dynamic } \\
\text { object organization }\end{array}$ & Reasoning Pattern \\
\hline Software & Classes & Methods & Rules \\
\hline
\end{tabular}

Table 2. Integration of the KOD method into the elaboration process of ontology.

\begin{tabular}{|c|c|c|}
\hline $\begin{array}{c}\text { Elaboration process of } \\
\text { Ontology }\end{array}$ & KOD process & $\begin{array}{c}\text { Elaboration process of } \\
\text { ontology with KOD }\end{array}$ \\
\hline $\begin{array}{ll}\text { 1. } & \text { Specification } \\
\text { 2. } & \text { Corpus definition } \\
\text { 3. } & \text { Linguistic study } \\
\text { 4. } & \text { Conceptualisation } \\
\text { 5. } & \text { Formalisation }\end{array}$ & $\begin{array}{ll}\text { 1. } & \text { Practical Model } \\
\text { 2. } & \text { Cognitive Model } \\
\text { 3. } & \text { Software Model }\end{array}$ & $\begin{array}{ll}\text { 1. } & \text { Specification } \\
\text { 2. } & \text { Corpus definition } \\
\text { 3. } & \text { Practical Model } \\
\text { 4. } & \text { Cognitive Model } \\
\text { 5. } & \text { Formalisation } \\
\text { 6. } & \text { Software Model }\end{array}$ \\
\hline
\end{tabular}




\section{ONTOLOGICAL ANALYSIS OF SUPPLY CHAINS}

\subsection{Ontology specification}

As discussed in paragraph 2, this work is not intended to develop an ontology but rather to understand disparities of views and definitions in the areas of supply chains and risks. In this sense, the ontological analysis will be conducted at a high level of abstraction and KOD will be implemented only for the representation paradigm.

\subsection{The corpus of the study}

The ontological analysis is based on a corpus of definitions (Table 3) supplemented by documents that specify the meaning of each of the terms in these definitions. These additional documents may come from the same authors or authors who have analyzed and discussed these same definitions.

The advantage of considering a corpus of definitions is that they are, in essence, a conceptual vision of their authors. That is, they are already the ultimate outcome of a work of abstraction and reflection on the domain. On the other hand, this choice is consistent with the objectives of this analysis, which are to acquire a clear, global and precise vision of the field without wanting to build a detailed ontology.

Given the large number of definitions, which emerge from the literature review, our choice was based on the following criteria:

- the competent authority of the authors (and thus of their definitions) within the scientific community. Thus, we have retained the definitions of the authors who are most often referenced;

- the exclusion of the financial and economic perspectives since they are outside our disciplinary field of competence;

- the compliance with the classification criteria of (Thierry and Bel 2001) which distinguish the "firm" perspective from the "product" perspective;

According to the "firm" perspective (definitions 6, 7 and 8 from Table 3 ), the supply chain is progressively apprehended by focusing on each company and determining all the other companies connected to it (depending on the customer-supplier link) whatever the product to be produced. In this case, the supply chain may be limited to a customer and a supplier, or it may be expanded by the fact that suppliers of the supplier and customers of the customer can always be identified. According to the "product" perspective (definitions 1, 2, $3,4,5,6$, and 9 from Table 3 ), the different actors in the supply chain and the different activities are identified by following a product from its initial state (often as raw material) to its final state (the finished product at customer). The chain is thus apprehended from end to end with respect to the product under consideration.
Table 3: The corpus of definitions

\section{Lee et Billington (1993)}

A supply chain is a network of facilities that performs the functions of procurement of material, transformation of material to intermediate and finished products, and distribution of finished products to customers.

\section{La Londe et al. (1994)}

A supply chain is a set of firms that pass materials forward.

Normally, several independent firms are involved in manufacturing a product and placing it in the hands of the end user in a supply chain (raw material and component producers, product assemblers, wholesalers, retailer merchants and transportation companies are all members of a supply chain).

\section{Ganeshan et Harrison, (1995)}

A supply chain is a network of facilities and distribution options that performs the functions of procurement of materials, transformation of these materials into intermediate and finished products, and the distribution of these finished products to customers.

\section{Rota (1998)}

A supply chain is the set of firms involved in the manufacturing, distribution and sales processes of the product, from the first supplier to the final customer.

\section{Lummus et Vokurka (1999)}

Supply chain can be stated as: all the activities involved in delivering a product from raw material through to the customer including sourcing raw materials and parts, manufacturing and assembly, warehousing and inventory tracking, order entry and order management, distribution across all channels, delivery to the customer, and the information systems necessary to monitor all of these activities.

6. Tsay et al. (1999)

A supply chain is two or more parties linked by a flow of goods, information and funds.

\section{Stadler et al (2000)}

A supply chain consists of two or more legally separated organizations, being linked by material, information and financial flows. These organizations may be firms producing parts, components and end products, logistic service providers and even the (ultimate) customer himself.

\section{Mentzer et al., (2001)}

A supply chain is defined as a set of three or more entities (organizations or individuals) directly involved in the upstream and downstream flows of products, services, finances, and/or information from a source to a customer.

\section{Supply Chain Council (2004)}

The supply chain is the continuation of the stages of production and distribution of a product from the suppliers of the suppliers of the producer to the customers of its customers.

\subsection{Corpus analysis}

This step consists in extracting from each definition and complementary documents of the corpus, all the elements that are relevant to the representation of supply chain.

Let us consider the (Lee and Billington 1993) definition $\left(\mathrm{n}^{\circ} 1\right.$, Table 3$)$, supplemented by (Botta-Genoulaz 2005) and (Bouchriha 2002) comments which are:

"Facilities can be storage units, production units, a whole set of storage and production units (factories), suppliers, distributors, customers, etc." 


\subsubsection{Extracting taxemes}

Modeling in the form of Taxemes consists in organizing the terms of the definition (and its comments) representing objects and concepts by means of binary predicates (binary relations): <Object, Attribute, Value $>$. Five types of predicative relations are defined: the relations Classifying (is-a, kind-of), Identifying (is), Descriptive (name of the property), Structural (iscomposed-of) and Situative (is-in, is -on, etc.).

In this study, only two predicative relations are relevant: the classifying and structural relations. The following taxemes have been extracted:

$<$ Supply Chain, kind-of, Facilities Network $>$

$<$ Facilities Network, is-composed-of, Facilities $>$

$<$ Storage Unit, kind-of, Facilities $>$

$<$ Warehouse, kind-of, Storage Unit $>$

$<$ Production Unit, kind-of, Facilities $>$

$<$ Supplier, kind-of, Facilities $>$

$<$ Distributor, kind-of, Facilities $>$

etc.

The systematic application of this analysis and modelling at the whole corpus, have led to obtain the Practical Model (PM) of each definition. The abstraction of the PMs (from Practical Models to Cognitive Model)(Table 1) made it possible to build the tree representations of the Figures 2, 3, 4, 5, 6 .

\subsubsection{The cognitive model}

To be coherent with the two supply chain definition perspectives (firm and product), the abstraction operation (for building the cognitive model), has been conducted specifically for each area of definitions. Figures 2, 3 and 4 are modelling supply chain definitions with the product perspective, and Figures 5 and 6 are modelling supply chain definitions with the firm perspective.

The two perspectives (firm and product) do not introduce a conceptual contradiction, but on the contrary, they are complementary. The firm approach broadens the scope of concepts while the product approach specifies them.

The enterprise approach introduces the concept of flows, which can be financial, informational, "service product" or "physical product". "They are the objects to be managed within the supply chains" (Lauras M. 2004). The product approach specifies the concept of a physical product.

From the point of view of definitions, a supply chain is considered as a network of firms consisting of a set of firms and flows. Flows establish customer / supplier relationships that are defined relative to each company. The notions of customer and supplier are properties that characterize each firm in the chain. A firm for which no supplier is defined is a source of the chain and a company for which there is no customer (relative to the product under consideration) is an end customer.

A supply chain can be limited to a customer and a supplier (the source and the end customer), as it can be extended by the fact that suppliers of suppliers and customers of customers can always be considered.

\section{ONTOLOGICAL ANALYSIS OF RISK AND VULNERABILITY}

The ontological analysis of Risk and Vulnerability has been conducted in the same way than for Supply chains. This section is limited to a discussion about the results of this analysis.

Work on vulnerability can be divided into two main categories today: so-called "biophysical" vulnerability and so-called "social" vulnerability. Biophysical vulnerability (of stakes) is determined by the nature of the hazard, its intensity, its probability, the level of exposure of the stakes and their physical sensitivity to the hazard. According to this approach, for each stake, it is possible to establish an evaluation of the damages (or consequences, cf Figure 7) according to the properties of the hazard (nature, intensity, probability), the sensitivity of the stakes to this hazard and their exposure. Social vulnerability, also called "organisational vulnerability", expresses an organization's ability (i) to anticipate the hazard, (ii) to face with emergency, (iii) to adapt its behavior during crisis, and (iv) to rebuild itself. Social vulnerability is thus directly related to the resilience and functioning of societies (Wisner et al. 2004) (Barroca 2013).

The shift from vulnerability to resilience or vice versa is not formalized because of the different definitions (Brey 2015). The implementation of these concepts in risk management appears to have differences in perspective centered on the notions of damage for vulnerability and notions of functional recovery and reconstruction for resilience (Lhomme et al. 2010). One is significant of the weaknesses of something (system, organization, etc.) and the other of its strengths.

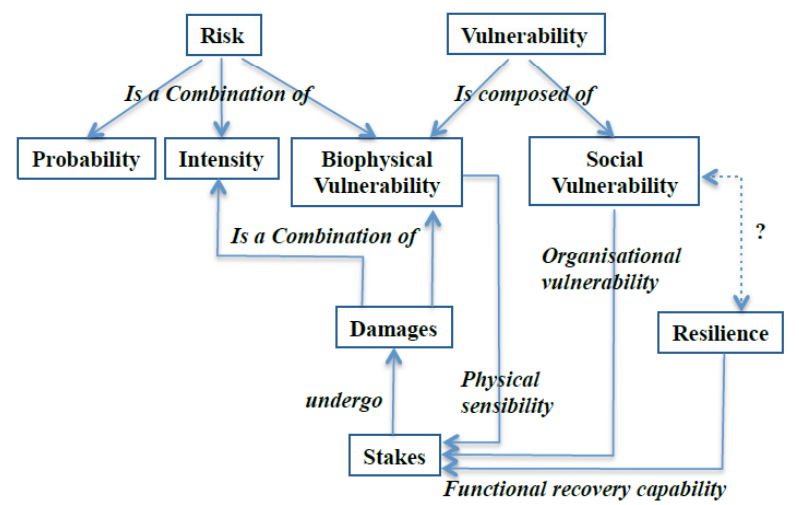

Figure 7: semantic network linking Risk and Vulnerability concepts. 


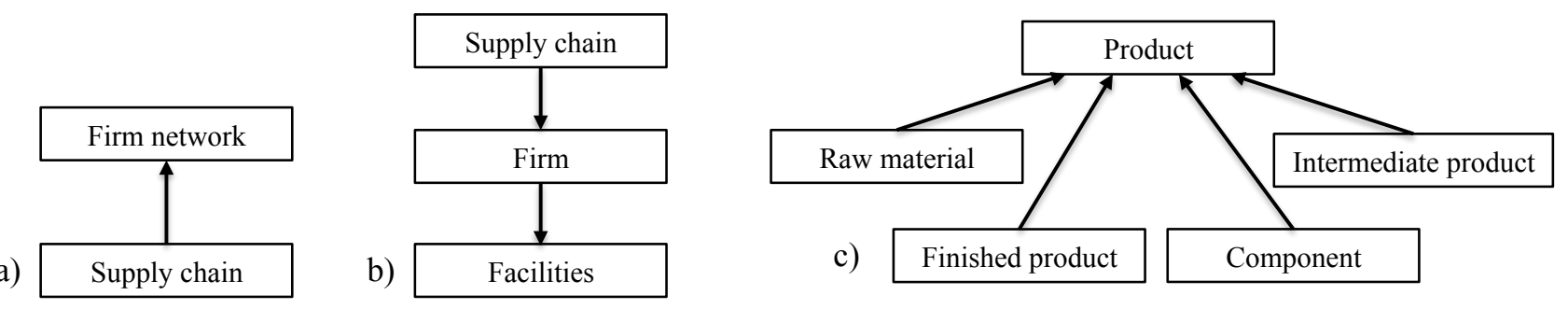

Figure 2: a) A Supply chain is a kind-of Firm network - b) A Supply chain is-composed-of Firm(s) and Firm iscomposed-of Facilities - c) Raw material, Finished product, Component and Intermediate product are kind-of Product.

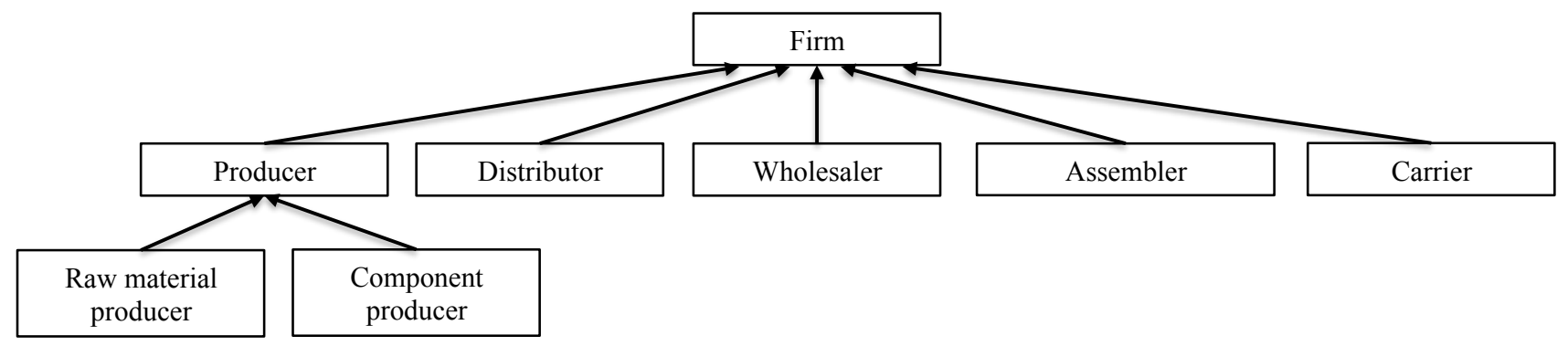

Figure 3: The Firm concept taxonomy (kinf-of relation). (Product perspective).

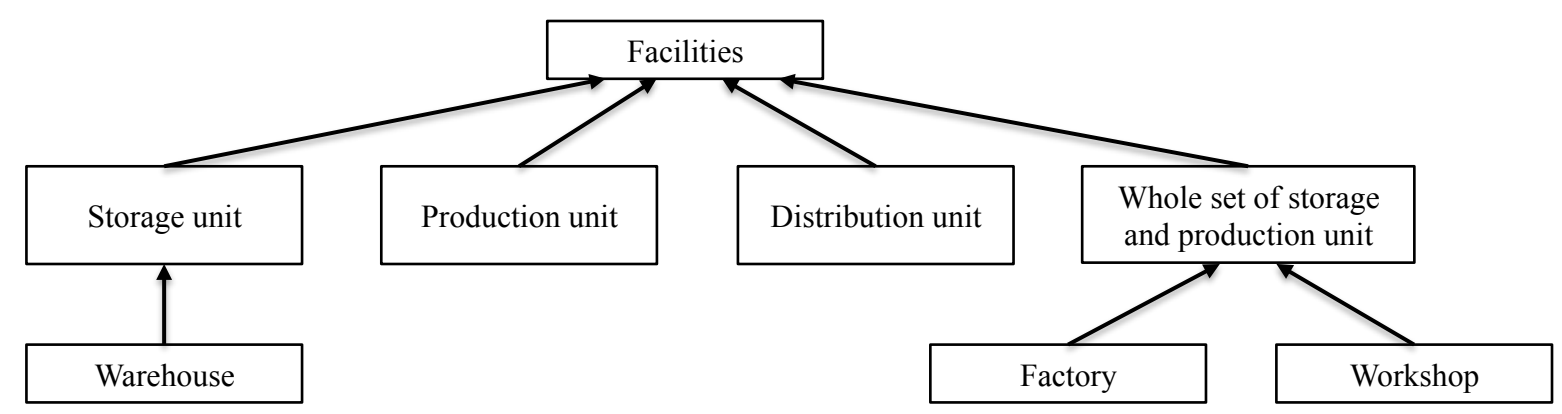

Figure 4: The Facilities concept taxonomy (kinf-of relation). (Product perspective).

a)

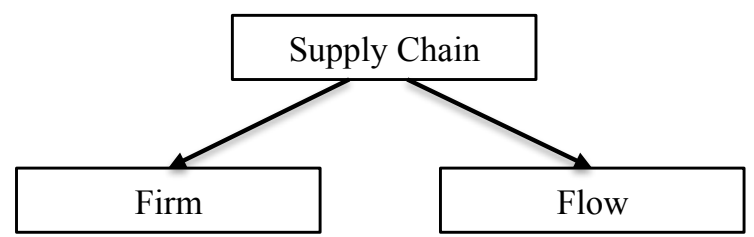

b)

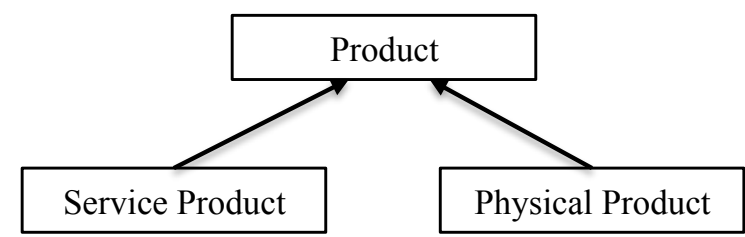

Figure 5: a) A Supply chain is-composed-of Firm(s) and Flow(s) - b) Service Product and Physical Product are kind-of Product. (Firm perspective).

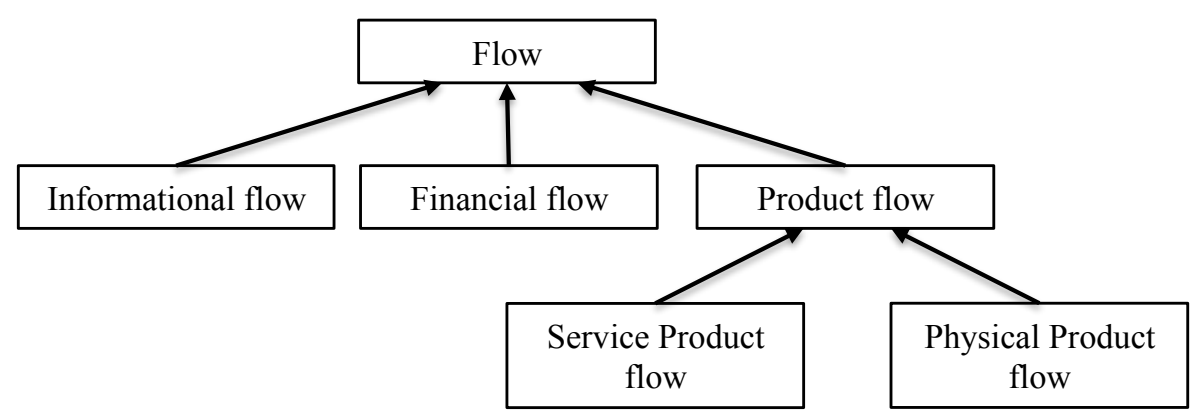

Figure 6: The Flow taxonomy (Firm perspective). 
A qualitative analysis of risk, as defined within the "safety engineering domain" show that risk is a combination of (Figure 7):

- the probability (likelihood) of something (hazard or disturbance) happening,

- the intensity of hazard or disturbance,

- the vulnerability of stakes according to the nature of hazards or disturbance.

And Damages are a combination of intensisty and vulnerability. By reducing the notion of combination to a multiplication, we can symbolically express the concept of Damage in the form of an equation:

\section{Vulnerability $=$ Damages / Intensity}

Variations in the relationship are consistent with the idea of Vulnerability. Something (or stake) is all the more vulnerable that the damage it undergoes is important for a given intensity of the disturbance. Similarly, something (or stake) is all the more vulnerable that the damage it suffers is due to a low intensity of the disturbance.

\section{SUPPLY CHAINS MODELLING}

\subsection{Introduction}

In this section, the formal model used for this study is presented. It is assumed that a supply chain is a series of facilities that exchanges flow (Figures 2.b, 4 and 5). Our modeling unit is a production unit or entity with its stock upstream. It is considered that this entity is autonomous and therefore akin to an independent firm. Each entity will be referred to as the stage.

A modular approach using ARIMA model (Box et Jenkins 1976) has been adapted to model supply chain dynamic and its flow exchanges (Figure 6). Each entity of the supply chain is modelled by its current stock quantity $I_{t}$ (at the date $t$ ) and its order policy. From this order policy and from knowledge about the end customer demand $\mathrm{D}_{\mathrm{t}}$, orders $\mathrm{O}_{\mathrm{t}}$ are set and the flow of information exchanged is given by $\mathrm{D}_{\mathrm{t}}$ and $\mathrm{O}_{\mathrm{t}}$. Finally, from an order issued at a date $\mathrm{t}-\mathrm{L}$, a physical product flow $\left(R_{t}\right)$ is received at the date $t$. The delivery lead time $\mathrm{L}$ is supposed fixed and known $(\mathrm{L}=\mathrm{do}+\mathrm{dp}+\mathrm{dd}$ (Table 5)).

Table 5: Conceptual interpretation of ARIMA variables

\begin{tabular}{|c|c|c|c|c|}
\hline \multicolumn{4}{|c|}{ Conceptual Entities (concepts and attributes) } & $\begin{array}{c}\text { ARIMA } \\
\text { variables }\end{array}$ \\
\hline \multirow{7}{*}{ FLOW } & \multirow{4}{*}{$\begin{array}{l}\text { Informational } \\
\text { Flow }\end{array}$} & \multirow{2}{*}{ Demand Flow } & $\begin{array}{l}\text { Current Customer } \\
\text { Demand }\end{array}$ & Dt \\
\hline & & & \begin{tabular}{|l|} 
Customer Demand \\
Average \\
\end{tabular} & $\mu$ \\
\hline & & \multirow{2}{*}{ Order Flow } & Quantity & Ot \\
\hline & & & Preparing Delay & do \\
\hline & \multirow{2}{*}{ Product Flow } & \begin{tabular}{|l|} 
Physical \\
Product Flow \\
\end{tabular} & Quantity & Rt \\
\hline & & \begin{tabular}{|l|} 
Service \\
Product Flow \\
\end{tabular} & & Not modelled \\
\hline & Financial Flow & & & Not modelled \\
\hline \multirow{4}{*}{ FIRM } & \multirow[b]{2}{*}{ Storage Unit } & & Current Stock Level & It \\
\hline & & & $\begin{array}{l}\text { Replenishment } \\
\text { Threshold }\end{array}$ & $\mathrm{s}$ \\
\hline & Product Unit & & Production Delay & $\mathrm{dp}$ \\
\hline & Distribution Unit & & Distribution Delay & $d d$ \\
\hline
\end{tabular}

In the following we present the modelling of a supply chain using ARIMA model. The class of ARIMA models is the most used representation of a time series. It is a combination of an autoregressive process (AR), an integrated process (I) and moving averages (MA) (Box and Jenkins 1976). When this process is stationary we talk about ARMA model. ARIMA models are built to represent the behavior of processes subject to random shocks over time. Random shocks represent random events (strikes, stock market crash, etc.), also known as disruptions, which affect the temporal behavior of these processes. Moreover the main purpose of this model is to predict the future values of the random process, taking into account its previous values observed.

\subsection{The ARIMA supply chain model}

Assuming that the demand is random and uncertain, in the form of an ARIMA (p, d, q) process (equation 1), and that the quantity of the products received at the date $\mathrm{t}$ is equal to the quantity of the products ordered at a date $\mathrm{t}-\mathrm{L}\left(\mathrm{R}_{\mathrm{t}}=\mathrm{O}_{\mathrm{t}-\mathrm{L}}\right)$, in (Graves 1999; Vuttichai 2004; Gilbert 2005; Gilbert et Vuttichai 2006; Hennet et Mercantini 2010; Sakli et al. (2014)) supply chain modeling is about formulating the demand $D_{t}$, the level of stock of $I_{t}$ (equation 2) the quantity of products or components to be ordered $\mathrm{O}_{t}$ taking into account forecast demand $\mathrm{D}_{\mathrm{t}+\mathrm{L}}$.

Moreover, from this presentation, and under « order up to policy » (Gilbert 2005) proved that the stock and order are also ARMA and discussed the causes of the bullwhip effect, a phenomenon in which variation in demand produces larger variations in upstream orders and inventory. This gives the dynamic of one stage of the supply chain.

A mathematical formulation of the demand $D_{t}$ can be constructed by the method of (Box and Jenkins 1976), where $\phi_{i}$ and $\theta_{i}$ are two identification parameters (Box et al. 2011) and $\varepsilon_{t}$ is a white noise.

$D_{t}=\mu+\sum_{i=1}^{n} \phi_{i}\left(D_{t-i}-\mu\right)+\varepsilon_{t}-\sum_{j=1}^{m} \theta_{j} \varepsilon_{t-j}$

Under «order up to policy », the inventory balance equation is written :

$I_{t}=I_{t-1}+O_{t-L}-D_{t}$

The quantity to be ordered represents the difference between the inventory level $\mathrm{S}$ and the position of the current inventory.

$O_{t}=S-I_{t}+\widehat{D}_{t}(1)+\cdots+\widehat{D}_{t}(L)-O_{t-1}-\cdots-O_{t-L+1}$

where $\widehat{D}_{t}(1)+\cdots+\widehat{D}_{t}(L)$ the previson of the demand in period $\mathrm{t}$ for the next $\mathrm{t}+1, \ldots, \mathrm{t}+\mathrm{L}$ periods.

To find the model of the whole chain, we iterate this model by assuming that the demand $D_{t}$ in an upstream stage is the order passed by the downstream stage $\mathrm{O}_{\mathrm{t}}$. This basic model can be used to model a multi-stage supply chain, put in series. The approach is to assume that the demand for an upstream stage is equal to the order quantity of the downstream stage. 


\subsection{A constrained ARIMA supply chain model}

The stationary behavior of an ARIMA model used for the representation of a supply chain is valid when the constraints of the companies forming the supply chain are respected.

In real cases, the company has a limited inventory capacity $(\bar{I})$ and cannot order more than a maximal amount of products from the supplier $(\bar{O})$. Also, the level of the stock and the quantity delivered cannot have negative values. To take these constraints into account, (Sakli et al. 2015) present a constrained ARMA model, in which the dynamic equations (2), (3) are respectively replaced by the following non-linear equations.

$\left\{I_{t}=\min \left(I_{t-1}+O_{t-L}-D_{t}, \bar{I}\right)\right.$

$\left\{I_{t}=\max \left(I_{t-1}+O_{t-L}-D_{t}, 0\right)\right.$

$\left\{O_{t}=\min \left(S-I_{t}+\widehat{D}_{t}(1)+\cdots+\widehat{D}_{t}(L)-O_{t-1}-\cdots-O_{t-L+1}, \bar{O}\right)\right.$

$\left\{O_{t}=\max \left(S-I_{t}+\widehat{D}_{t}(1)+\cdots+\widehat{D}_{t}(L)-O_{t-1}-\cdots-O_{t-L+1}, 0\right)\right.$

\subsection{Vulnerabilities indicators}

The study of the vulnerability of the system facing an undesirable event is necessary when the supply chain is deviated with respect to its objectives (reliability, responsiveness, etc).

It is extremely important to follow stock movements in order to avoid to have too much stock (immobilized money, risk of obsolescence of the articles which leads to a loss of money) or to be in stock-outs situation (loss of turnover, very bad for the brand image).

Vulnerabilies indicators can be calculated by evaluating the damage of the disturbance and its intensity (Hennet et Mercantini 2010): an Inventory cost indicator (ICostInd), a total Cost indicator for the stage (CostInd), an indicator of excess products (Lind) and a Supply limit indicator (SInd).

\section{SIMULATION}

The purpose of this simulation is the implementation of the indicators facing the disruption of demand. To do this we assume that the D demand is

$D_{t}=0.5 D_{t-1}+0.5 D_{t-2}+\varepsilon_{t}$

$\varepsilon_{t}$ is a Gaussian white noise of zero mean and standard deviation $\sigma^{2}=5$. The dynamic of the demand and its prediction are shown in the figure 8 .

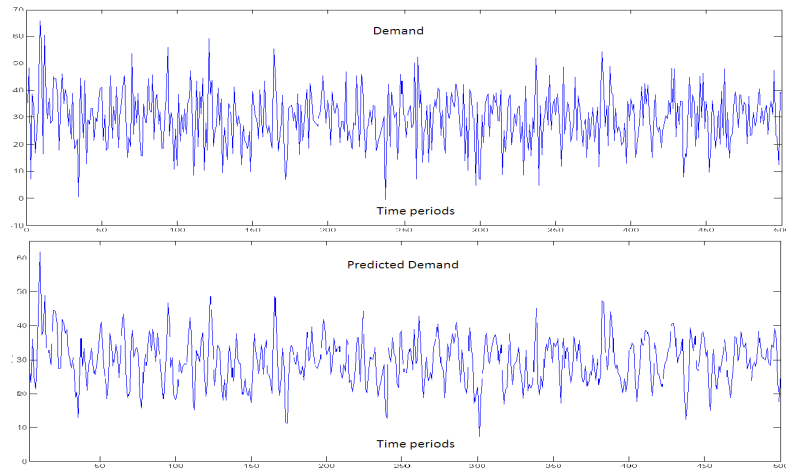

Figure 8: dynamic of the demand and its prediction
To illustrate the effect of the demand disruption, we take this example again. The same average demand is maintained and its Standard deviation is modified to obtain the three scenarios of the table 5 .

Table 6: the three scenarios of the demand.

\begin{tabular}{|c|c|c|}
\hline Scenario & Demand & Standard deviation \\
\hline 1 & D1 & 10 \\
2 & D2 & 7,5 \\
3 & D3 & 5 \\
\hline
\end{tabular}

With the values: $S=45, L=3, \bar{I}=45$, et $\bar{O}=55$

To compare the behavior of these three demands through the proposed indicators, the following table groups together the different results obtained, assuming that the sliding observation window $\mathrm{d}=500$.

Table 7: simulation results.

\begin{tabular}{|l|l|l|l|l|}
\hline Scenario & ICostInd & CostInd & Lind & SInd \\
\hline 1 & 0.0805 & 0.2140 & 0.1177 & 0.3939 \\
2 & 0.0199 & 0.1204 & 0.0540 & 0.3531 \\
3 & 0.0120 & 0.1063 & 0.0240 & 0.2109 \\
\hline
\end{tabular}

From this table we can deduce that the more the demand is fluctuating, the more the system arrives at states of imbalance and therefore becomes vulnerable to adverse events. The interest of these indicators is to evaluate the disturbances resulting from the expected objectives in terms of performances. Periodic observations of these indicators can highlight changes in existing imbalances and also reveal potential imbalances monitoring and detection of drift that require risk-related decisions.

\section{CONCLUSION}

This paper presents the process employed in obtaining conceptual models of supply chains facing risk situations. The process is based on the analysis of academic and return on experience documents according to the knowledge acquisition method KOD. The resulting conceptual model has been used to build a multi-stage supply chain model based on ARIMA (Auto Regressive Integrated Moving Average) models incorporating the demand randomness. Finally, supply chain vulnerability has been studied thank to the simulation of critical scenarios. The results characterize the effect of demand variability on stock level and order quantity on the upstream stage.

\section{REFERENCES}

Aussenac-Gilles N., Biébow B. and Szulman S., 2000. Revisiting Ontology Design: a method based on corpus analysis. EKAW-2000, Proceedings of the $12^{\text {th }}$ International Conference on Knowledge Engineering and Knowledge Management, R. Dieng et O. Corby (éd.), LNAI 1937, Springer, pp. 172-188.

Barroca B., DiNardo M., Mboumoua I., 2013. De la vulnérabilité à la résilience: mutation ou bouleversement? EchoGéo [En ligne], 24 / 2013. 
URL : http://echogeo.revues.org/13439 ; DOI:10.4000/echogeo.13439.

Botta-Genoulaz V., 2005. Principes et méthodes pour l'intégration et l'optimisation du pilotage des systèmes de production et des chaînes logistiques. HDR. Institut National des Sciences Appliquées de Lyon et Université Claude Bernard de Lyon 1.

Borst P. et H. Akkermans. An ontology approach to product disassembly. In International Conference on Knowledge Engineering and Knowledge Management. October 1997: 33-48.

Bouchriha H., 2002. Faire ou faire-faire dans la conception d'une chaîne logistique: un outil d'aide à la décision. Doctoral dissertation. Institut National Polytechnique de Grenoble-INPG.

Box G.E.P. et Jenkins G.M., 1976. Time series analysis forecasting and control. Holden-Day.

Box G.E.P., Jenkins G.M., Reinsel G.C., 2011. Time series analysis: forecasting and control. Time series analysis: forecasting and control, (John Wiley \& Sons), Vol. 734.

Caroll J.M., 1997. Scenario-Based Design. In M. Helander, T.K. Landauer, P. Prabhu (Ed.), Handbook of Human-Computer Interaction (Chapter 17). Second completely revised edition, Elsevier Science B.V.

Chopra S. \& Sodhi M.S., 2004. Managing risk to avoid supply-chain breakdown. MIT Sloan Management Review (Fall 2004).

Dahlgren K. 1995. A Linguistic Ontology. International Journal of Human-Computer Studies, vol. 43, n5, pp. 809-818.

Gandon F., 2002. Ontology engineering: a survey and a return on experience. Research Report $n^{\circ} 4396$. INRIA Sophia-Antipolis, mars 2002.

Gilbert K., 2005. An ARIMA supply chain model. Management Science 51.2 (2005): 305-310.

Gruber T.R., 1993. A translation approach to portable ontology specifications. Knowledge acquisition, pp 199-220.

Haywood M., 2002. An investigation into supply chain vulnerability management within UK aerospace manufacturing supply chains. MSc thesis, Cranfield University, 2002.

Hennet, J.-C. \& Mercantini J.-M., 2010. Modeling and evaluation of vulnerabilities in a supply chain. $8^{\text {th }}$ International Conference of Modeling and Simulation. MOSIM'10, May 10-12, 2010.

Juttner U., Peck H., Christopher M., 2003. Supply chain risk management: outlining an agenda for future research. International Journal of Logistics: Research and Applications 6.4 (2003): 197-210.

Lauras M., et al., 2003. Référentiel de l'entente industrielle : 3 approches dans le domaine de la gestion des chaînes logistiques. 5ème Congrès International de Génie Industriel octobre 2003.

Lee H.L. et Billington C., 1993. Material management in decentralized supply chain. Operations Research 41.5 .
Lhomme S., Serre D., Diab Y., Laganier R., 2010. Les réseaux techniques face aux inondations ou comment définir des indicateurs de performance de ces réseaux pour évaluer la résilience urbaine, Bulletin de l'Association de Géographes Français, pp 487-502.

Mercantini J.-M., Capus L., Chouraqui E., Tourigny N., 2003. Knowledge Engineering contributions in traffic road accident analysis. In: Ravi K. Jain, Ajith Abraham, Colette Faucher, Berend Jan Van der Zwaag, eds. Innovations in Knowledge Engineering. pp 211-244.

Mercantini J.-M., Turnell M.F.Q.V, Guerrero C.V.S, Chouraqui E., Vieira F.A.Q et Pereira M.R.B, 2004. Human centred modelling of incident scenarios. IEEE SMC 2004, Proceedings of the International Conference on Systems, Man \& Cybernetics, pp. 893-898. October 10-13, The Hague, The Netherlands.

Mercantini JM., Tourigny N., Chouraqui E., 2007. Elaboration d'ontologies à partir de corpus en utilisant la méthode d'ingénierie des connaissances KOD. $1^{\text {ère }}$ édition des Journées Francophones sur les Ontologies (JFO 2007), $n^{\circ}$ ISBN : 978-997337-414-1, pp 195-214, 18 - 20 Octobre 2007, Sousse (Tunisie).

Mercantini J.-M., 2015. Building a domain ontology to design a decision support software to plan fight actions against marine pollutions. In: SpringerVerlag, Risk and Cognition, Mercantini JM. and Faucher C. (Editors). Intelligent Systems Reference Library, Vol. 80, January 2015.

Sakli L., Hennet J.-C., Mercantini J.-M., 2014. An Analysis of Risks and Vulnerabilities in Supply Networks. World Congress 19.1, 8933-8938.

Sakli L., Hennet J.-C., Mercantini J.-M., 2015. Impact of Changes in Quality of Deliveries on the Vulnerability of Supply Chains. Risks and Resilience of Collaborative Networks. Springer International Publishing, pp. 578-587.

Thierry C. \& Bel G., 2002. Gestion de chaines logistiques dans le domaine aéronautique : outils d'aide a la décision pour l'amélioration du partenariat. Revue Française de Gestion Industriel.

Uschold M. and King M., 1995. Towards a Methodology for Building Ontologies. Proceedings of the IJCAI-95 Worshop on Basic Ontological Issues in Knowledge Sharing, Montréal (Canada).

Uschold M. and Grüninger M., 1996. Ontologies: Principles, methods and applications. Knowledge Engineering Review, volume 11, n 2, pp. 93-136.

Vogel C., 1988. Génie cognitive. Paris, Masson (Sciences cognitives).

Zsidisin G., 2003. Managerial perception of risk. Journal of Supply Chain Management. pp 14-25. 